\title{
Cryotherapy for advanced carcinoma of the trachea and bronchi
}

\author{
M O MAIWAND
}

\begin{abstract}
Cryotherapy was used to relieve symptoms in 75 patients suffering from advanced carcinoma of the trachea or bronchi. In all patients surgical resection, radiotherapy, or chemotherapy had been tried and been unsuccessful or had been thought to be unsuitable because of the patients' poor general condition. In cryotherapy the intraluminal tumour was frozen through a Stortz bronchoscope. Localised necrosis increased the patency of the lumen of the trachea or bronchi, resulting in relief of symptoms.

Cryotherapy is effective and easily performed and causes the patient little discomfort.
\end{abstract}

\section{Introduction}

Freezing has been used to treat tumours for many years..$^{1-4}$ It is safe, causes little trauma, and is easily controlled. Different cooling agents have been used, including liquid nitrogen, nitrous oxide, carbon dioxide, and fluorinated hydrocarbons such as Freon. Each agent gives a different degree of freezing at the tip of the cryoprobe.

The freezing of tissue causes the formation of ice crystals both inside and outside cells, cellular dehydration, intracellular electrolyte changes, and denaturation of membranous lipoprotein, leading to cell death ${ }^{4-6}$ The mass of tissue destroyed seems to depend on the size of the ice ball formed, the rate and degree of fall in temperature, the diameter of the probe, and the number and duration of freezethaw cycles. ${ }^{47}$ Subjecting normal or malignant cells to a temperature of $-20^{\circ} \mathrm{C}$ or lower for one minute or longer causes cell necrosis. ${ }^{48} \mathrm{~A}$ rapid freeze followed by a slow thaw seems to be an effective method of destroying cells. ${ }^{49}$

\footnotetext{
Thoracic and Cardiac Surgical Unit, Harefield Hospital, Harefield, Uxbridge, Middlesex UB9 6JH

M O MAIWAND, MD, thoracic surgeon
}

In man bronchoscopic cryotherapy with liquid nitrogen has shown promise in the local control of bronchial tumours ${ }^{10}$ Animal experiments have shown that cryotherapy within the trachea or bronchial tree is safe. ${ }^{11-15}$ Our aim in using cryotherapy was to relieve some of the symptoms associated with advanced lesions of the trachea or bronchi when conventional methods had failed or were unsuitable.

\section{Patients and methods}

Seventy five patients (54 men, 21 women; mean age 63 (range 29-80)) presenting with haemoptysis or obstruction of the trachea or bronchi, or both, by a tumour were treated by cryotherapy. In 18 the endobronchial tumour had recurred after lung resection. In 16 tumour growth had continued after radiotherapy, and in eight the tumour had recurred after lung resection and radiotherapy. For 33 patients cryotherapy was chosen as the first treatment because of their poor general condition.

The main presenting symptoms and the position of the tumour differed between patients (see table I). The sites of the tumour were the trachea ( 24 patients), the right or left main bronchus (21), the right upper lobe bronchus (nine), the left upper lobe bronchus (eight), the right lower lobe (six), and the left lower lobe (four). Three patients had a multifocal tumour.

TABLE I-Effect of cryotherapy on symptoms and obstructions. Figures are numbers of patients

\begin{tabular}{|c|c|c|}
\hline & $\begin{array}{l}\text { Patients } \\
\text { affected before } \\
\text { treatment }\end{array}$ & $\begin{array}{c}\text { Patients } \\
\text { improved after } \\
\text { treatment }\end{array}$ \\
\hline \multicolumn{3}{|c|}{ Main presenting symptom } \\
\hline Stridor & 33 & 20 \\
\hline Dyspnoea & 31 & 23 \\
\hline \multirow{2}{*}{\multicolumn{3}{|c|}{ Principal obstruction }} \\
\hline & & \\
\hline Intraluminal & 54 & $54 \dagger$ \\
\hline
\end{tabular}

*Haemoptysis completely resolved in seven patients.

IIn seven no visible obstruction remained after treatment; in 22 the patency of the lumen increased by about $20 \%$ after the first treatment session; in 25 the patency increased by about $35 \%$ after two or more treatment sessions. 
The decision to use cryotherapy was made during bronchoscopy. The procedure was explained to the patients, who gave informed consent. After general anaesthesia a Stortz bronchoscope (No 9) was introduced. Oxygenation was maintained by Venturi positive pressure ventilation. Tissue samples for histological examination were taken from all patients before treatment.

To obtain maximum contact between the probe and the tumour two new probes were designed, their shape being determined by the anatomy of the bronchial tree (figure). One, with an angled tip, was used for lesions of the trachea, main bronchi, and basal segments of the lower lobes. The other with a right angled tip, was used for lesions in the upper lobes and the apical segments of the lower lobes.

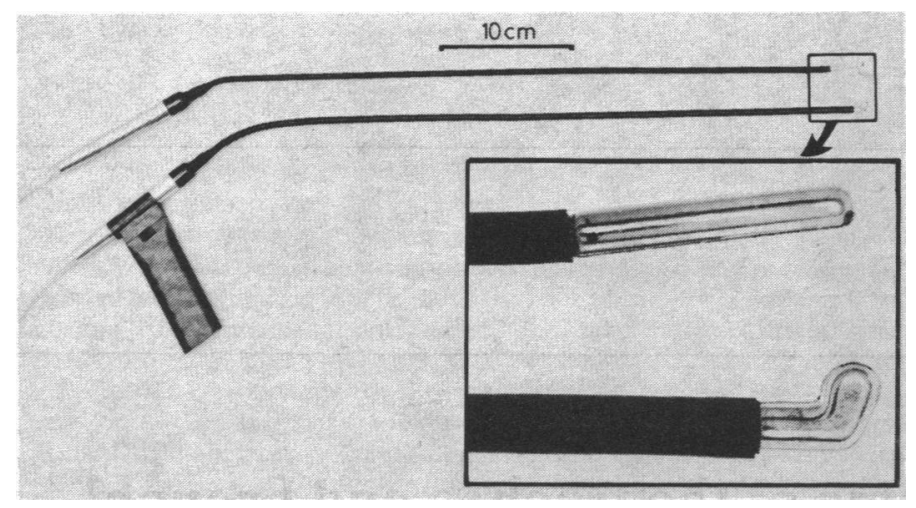

Bronchial cryoprobes, showing slightly angled tip and right angled tip.

Continuous endobronchial suction through a long catheter with an external diameter of $3 \mathrm{~mm}$ was maintained as required, removing blood and secretions from the area under operation to allow good contact between the probe and the tumour. A Spembly 140 Medical cryomachine ensured a minimum temperature of about $-70^{\circ} \mathrm{C}$ at the tip of the cryoprobe, achieved by the Joule-Thomson effect of the nitrous oxide through a restrictive nozzle within the chambers of the tip. ${ }^{16}$ The probe was placed on or in the tumour mass. After freezing of the tumour for 150 seconds a uniform ice ball could be seen around the tip of the probe. Thawing was allowed to take place until the probe separated from the tissue. The tumour was then refrozen at the same site for a further 150 seconds. There was no evidence of bronchial oedema after the operation, and steroids were not given.

As much as possible of the intraluminal tumour was removed by forceps. Bleeding from the site of biopsy was controlled, if necessary, by local application of adrenaline solution $1 / 1000$. Local necrosis of the intraluminal tumour caused by cryotherapy made removal of dead tissue by forceps easier at the next treatment. The treatment was repeated at intervals of about two, four, and eight weeks, depending on the patient's response and the clinical findings. Biopsy samples were taken from the affected area before each treatment. In all, the 75 patients received 202 cryotreatments.

\section{Results}

Table I shows the effects of cryotherapy on the main presenting symptoms and the principal obstruction. Table II shows the relation between the type of tumour cell and survival of the patient. The condition of 12 patients did not improve, six patients continued to deteriorate, and one patient died from a non-surgical cause. In eight patients who had had complete collapse of one lung before treatment subsequent chest $x$ ray films showed sustained reinflation of the lung. In a further six patients the lung re-expanded for five to six weeks. In five patients in whom tumour had recurred in the bronchial stump after pneumonectomy or lobectomy cryotherapy eradicated macroscopic tumour and no malignant cells were identified in the repeat biopsy samples at varying time intervals later.

No more pain or discomfort occurred after treatment than would have occurred after bronchoscopy. No cardiovascular complications occurred. The entire procedure took about 10-15 minutes.
TABLE II-Histological findings related to survival. Figures are numbers of patients

\begin{tabular}{|c|c|c|c|c|c|c|c|}
\hline \multirow[b]{2}{*}{ Tumour cell type } & \multirow{2}{*}{$\begin{array}{c}\text { Started } \\
\text { treatment }\end{array}$} & \multicolumn{6}{|c|}{ Survival (months) } \\
\hline & & $<1$ & $1-2$ & $3-5$ & $6-8$ & $9-11$ & $\geqslant 12$ \\
\hline \multirow{5}{*}{$\begin{array}{l}\text { Squamous cell carcinoma } \\
\text { Adeno cell carcinoma } \\
\text { Undifferentiated large cell } \\
\text { carcinoma } \\
\text { Undifferentiated small cell } \\
\text { carcinoma }\end{array}$} & 45 & 8 & 12 & 7 & 2 & 2 & 14 \\
\hline & 7 & 3 & 3 & - & - & - & 1 \\
\hline & 18 & 6 & 4 & 6 & 1 & - & 1 \\
\hline & & & & & & & \\
\hline & & & & & & & \\
\hline Total & 75 & 18 & 21 & 14 & 4 & 2 & 16 \\
\hline
\end{tabular}

\section{Discussion}

Experience has shown that tumour necrosis caused by cryotherapy results in increased patency of the airway. Delay in regrowth of the lesion retards further obstruction of the bronchial tree. The relief of breathlessness results in a better quality of life. Haemoptysis, a distressing symptom of non-resectable bronchial tumours, is not easily treated, and cryotherapy offers an effective means of controlling bleeding in such patients. It is cheap and easier to use than laser therapy. As expected, the results were gratifying in patients whose tumour was within the lumen of the tracheobronchial tree. In those with extrinsic compression a tracheobronchial stent is a more effective method of obtaining immediate relief of tracheal or major bronchial obstruction. ${ }^{17}$

The use of liquid nitrogen as a refrigerant was considered, but this can give temperatures at the tip of the probe as low as $-196^{\circ} \mathrm{C}$ and can cause much unwanted destruction of tissue. ${ }^{18}$ The greater degree of control offered by using nitrous oxide as the freezing agent avoids damage to adjacent vital structures.

The initial results with this technique are encouraging and suggest that cryotherapy has a place in the relief of symptoms of advanced tracheobronchial lesions.

I thank all the staff at Colindale Hospital; Dr J McAlpine, consultant histopathologist; colleagues who have given their support; and Spembly Limited of Andover for technical cooperation.

\section{References}

1 Arnot J. On the mode of applying cold efficiently in diseases of the uterus. Medical Times Gazette 1857;14:307-8

2 Pussey WA. The use of carbon dioxide snow in the treatment of nevi and other lesions of the skin: a preliminary report. JAMA 1907;49:1354-6.

3 Smith LW, Fay T. Temperature factors in cancer and embryonal cell growth. JAMA 1939;113:653-60.

4 Nell HB. Cryosurgery for the treatment of cancer. Laryngoscope 1980;90(8 pt2):1-48.

5 Pegg DE. Cryobiology. Physics in Medicine and Biology 1966;11:209-24.

6 Cooper IS. Cryogenic surgery: a new method of destruction or extirpation of benign or malignant tissues. N Engl I Med 1963;268:743-9.

7 Gill WL, Fraser J, Lee P. Cryosurgery for neoplasia. Br 7 Surgery 1970;57:494-502.

8 Gage AA. What temperature is lethal for cells? J Dermatol Surg Oncol 1979;5:459-60.

9 Gill W, Fraser J, Carter DC. Repeated freeze thaw cycles in cryosurgery. Nature 1968;219:410-3.

10 Sundeson DR, Nell HB, Fontana RJ. Bronchoscopic cryotherapy. Ann Otol Rhinol Lanyngol 1981;90:354-458.

11 Thomford NR, Willson WH, Blackburn ED, Page WG. Morphological changes in canine trachea after freezing. Cryobiology 1970;7:19-26.

12 Nell HB, Farrell KH, Desanto LW, Paynes WS. Cryosurgery of respiratory structures. I. Cryonecrosis of trachea and bronchus. Lanyngoscope 1973;83:1062-71.

13 Nell HB, Farrell KH, Paynes WS. Cryosurgery of respiratory structures. II. Cryonecrosis of the lung. Laryngoscope 1974;84:417-26.

14 Skivolocke WP, Page WG, Thomford NR. Effect of cryotherapy on tracheal tumours in rats. Arch Surg 1971;103:341-4.

15 Carpenter RJ, Neel HB, Sunderson DR. Cryosurgery of bronchopulmonary structures: an approach to lesions inaccessible to the rigid bronchoscope. Chest 1977;72:279-84.

16 Meldrum SJ. Some aspects of cryosurgery. Biomedical Engineering 1970;5:120-4.

17 Westaby S, Jackson JW, Pearson FG. A bifurcated silicone rubber stent for relief of tracheobronchial obstruction. Thorac Cardiovasc Surg 1982;83:414-7.

18 Holden HB. Cryosurgery: its scientific basis and clinical application. Practitioner 1973;210: 543-50.

(Accepted 24 April 1986) 